substance. Preliminary experiments on the electrodialysis of vitamin $\mathrm{B}_{2}$, earried out with $\mathrm{Mr}$. T. W. Birch, also appear to support this conclusion. These fractionation experiments have given the general impression that vitamin $B_{2}$ is fairly readily adsorbed by neutral precipitates. Thus, the partial precipitation by lead acetate and also by silver nitrate is probably merely due to the adsorption of the vitamin on to the precipitates formed.

'Though the liver extract is potent in both vitamin $B_{2}$ and the factor specific for pernicious anæmia, they appear to be different from evidence of the methods of their fractionation and also on other grounds.

The stability of vitamin $\mathrm{B}_{2}$ to heating under pressure in an alkaline medium shows curious discrepancies. Commercial liver concentrate and commercial yeast extract ('marmite') are both fairly stable to autoclaving at $p \mathrm{H} 9$ at $124^{\circ} \mathrm{C}$., while aqueous extracts made from brewer's yeast, fresh ox liver, and ox muscle are markedly unstable under the same conditions. The stability appears to be connected with the presence of certain protective materials in a given fraction.

The vitamin is stable to sulphur dioxide, hydrogen peroxide, and ozone.

Biochemical Laboratory, B. C. GuHA. Cambridge.

\section{Embryology and Evolution.}

Dr. A. Piney, in his letter to Nature of Feb. 28, accuses me of reviving a dormant form of vitalism, but with the deification of entelechy I certainly have no association. He says, "The sterility of vitalistic hypotheses in the past leads one to doubt their fertility in the future ", but the fecundity of alterna. tive hypotheses is not conspicuous.

Dr. Piney defines science in modo et forma with masterly assurance that the man of science has no concern with what lies outside his conceptual schemes, yet the actual instability of such schemes indicates that the real motive of the scientific worker is the attempt to discover what Dr. Piney himself admits may be of the greatest importance.

As biologists, whether we incline to the belief that the living cell is something self-contained and perfectly unique in the universe, or whether we suspect that it, in common with the rest of matter, is subject to obscure external forces, our confession in regard to the control of vital processes, so far, is one of ignorance. But those of us who feel that the living cell is a machine in miniature, the very life of which depends, as a familiar fact, upon its reception of electromagnetic radiations of the order 8000 to $4 \times 10^{6} \mathrm{~A}$., may perhaps be pardoned for suspecting that the protoplasmic cogs are driven by external forces, even though we profess no adherence to the views of the great Nicholas of Cusa.

Malcolm E. Macgregor.

Wellcome Field Laboratory,

Wisley, Surrey, Mar. 21.

\section{High-flying Egrets at Night.}

Astronomicar and ornithological readers of NATURE may be interested to hear of a somewhat extraordinary experience I had rather early in the morning of Feb. 16 while sweeping for comets. About 12.30 A.M. I was suddenly startled to see in the field of view of my $7 \frac{3}{4}$-inch reflector, using an eyepiece giving about 35 power, about twelve to fifteen large golden-coloured objects, like third magnitude stars much out of focus, and thus enlarged, crossing the field at a fair pace. At first I wondered what it could be. It was as if a star cluster like the Pleiades had suddenly taken to flight. I soon recognised as I followed the objects in the telescope that they were a flight of the little white egrets, passing a little more than a mile away, and so high up that the electric lights of the city lit up the under side of their wings, giving them a golden colour like stars. I followed them for about two minutes, first in the reflector and then in the finder, until they got out of my reach towards the west. When first I saw them they were perhaps a little to the east of the Southern Cross, and about the same altitude, say $45^{\circ}-50^{\circ}$. They travelled west and passed $4^{\circ}$ or $5^{\circ}$ below Canopus, and then I lost them, as they got too far west for my balcony.

These egrets are often seen in these parts following cattle and eating the flies in their track or on their bodies. It would be interesting to know if anyone has seen such a thing at night before. They were flying in a wedge shape, and I could see the motion of their wings, probably about one mile high and one mile away. Of course, in the daytime birds have been seen crossing the sun's disc, but this was midnight.

\section{Theodore B. BцathWayt.}

\section{P.O. Box 7532, Johannesburg,} Feb. 16.

\section{Fine Structure in the Mercury Singlet Terms : A Correction.}

I WISH to direct attention to an error in the particulars I have recently given ${ }^{1}$ of the fine structure of the line $\lambda 6234\left(7^{1} S_{0}-91 P_{1}\right)$ in mercury. The positions of the components $g$ and $f$, given as -0.406 and $-0.696 \mathrm{~cm} .^{-1}$, are actually -0.306 and -0.544 . The diagram in Fig. 2 requires a corresponding emendation. The corrected value 306 for the interval $b f$ in $7^{1} S_{0}-9^{1} P_{1}$ now agrees reasonably well with the interval 308 (be) of $\lambda 5676\left(7^{3} S_{1}-9^{1} P_{1}\right)$, and its previous allocation to the $9^{1} P_{1}$ level is thus confirmed. Further, the intervals $31,121,156$ which occur in the $9^{1} P_{1}$ term are now seen to be consecutive since their sum, 308, is established as a real difference. The main conclusions reached in the paper are not affected by the error.

\section{S. Tolansky.}

\section{Physies Department, Armstrong College}

(University of Durham), Newcastle-on-Tyne,

$$
\text { Mar. } 25 .
$$

1 Proc. Roy. Soc., A, 130, 559; 1931.

\section{The Theory of Geological Thermal Gycles.}

Dr. J. H. J. Poole's opening paragraph (NATURE, April 4, p. 518) suggests that in my first criticism of Prof. Joly's theory I did not consider the possible effects of fusion in the production of periodicity. On the contrary, the main topic of the paper was to discuss whether fusion could have such an effect ; and none was found.

I need scarcely say that I do not share Dr. Poole's doubt as to whether a fluid, with internal generation of heat, would maintain the adiabatic gradient of tem. perature. There is abundant theoretical reason for this, and it is in accordance with meteorological experience.

St. John's College,

Harold JefFreys.

No. 3207, VoL. 127] Cambridge. 